\title{
Development of Cutaneous Bioadhesive Ureasil-Polyether Hybrid Films
}

\author{
João Augusto Oshiro Junior, Flávia Chiva Carvalho, Christiane Pienna Soares, \\ Marlus Chorilli, and Leila Aparecida Chiavacci
}

Pharmaceutical Sciences School of São Paulo State University (UNESP), Araraquara-Jaú Interstate Highway, Km 1, 14801-902 Araraquara, SP, Brazil

Correspondence should be addressed to Leila Aparecida Chiavacci; leila@fcfar.unesp.br

Received 8 December 2014; Accepted 26 January 2015

Academic Editor: Alenka Vesel

Copyright (C) 2015 João Augusto Oshiro Junior et al. This is an open access article distributed under the Creative Commons Attribution License, which permits unrestricted use, distribution, and reproduction in any medium, provided the original work is properly cited.

\begin{abstract}
The hydrolysis and condensation reactions involved in synthesis of ureasil-polyether films influence the film formation time and the number of chemical groups able to form hydrogen bonds, responsible for the bioadhesion, with the biological substrate. The objective of this work was to study the influence of the use of an acid catalyst (hydrochloric acid) and a basic catalyst (ammonium fluoride) in the hydrolysis and condensation reactions on the time formation and bioadhesion of ureasil-polyether films. The toxicity of the films was evaluated. The MTT assay has shown cell viability of human skin keratinocytes higher than $70 \%$ of all analyzed materials suggesting low cytotoxicity. The bioadhesion of the films is strongly dependent on the viscosity and hydrophilic/hydrophobic balance of the polyether chains used to synthetize the hybrid molecules. The use of acid catalyst promotes the formation of less viscous films with higher bioadhesion. The hybrids formed by more hydrophilic PEO chains are more bioadherent, since they can interact more efficiently with the water present in the stratum corneum increasing the bioadhesion. Due to their low toxicity and high bioadhesion, the ureasil-PEO films obtained by using $\mathrm{HCl}$ as catalyst agent are good candidates for application to the skin as bioadhesive films.
\end{abstract}

\section{Introduction}

Several types of polymeric materials have been studied over the last decade, in order to form bioadhesive films for controlled release of drugs through the skin $[1,2]$. These devices can improve the bioavailability of drugs that suffer presystemic hepatic metabolism when administered orally and consequently optimize the pharmacotherapy, since they can maintain the correct concentration in the plasma, thus not requiring multiple daily administrations [3]. Bioadhesive films can be applied to a variety of drugs, are of low cost and easy to apply, and allow immediate discontinuation of treatment for some side effect.

For polymeric materials to be employed as films for cutaneous applications, they must show bioadhesion, which is the property of adhering and remaining in contact with the skin for an extended period of time $[4,5]$. Bioadhesive film formers can also be used to control drug release and for this purpose the materials must have the following characteristics: (a) sufficient chemical groups capable of forming hydrogen bonds $(\mathrm{OH}$ and $\mathrm{COOH}$, e.g.) to the biological substrate; (b) high molecular mass, which is related to the size of the polymer chain; (c) high flexibility of the polymer chain, because low flexibility leads to wrinkling of the film on the skin, decreasing its bioadhesiveness; and (d) suitable surface tension to induce the diffusion of the drug through the layer of epithelial tissue $[6,7]$.

Many polymers have been investigated for use as mucoadhesive systems, but there are few reports in the literature about the mechanisms involved in the process of bioadhesion when the biological substrate is skin. A study involving materials based on polyethylene oxide demonstrated that functional groups such as $\mathrm{COOH}$ are strongly correlated with the bioadhesive process on the oral mucosa, since high moisture at the site favours the formation of hydrogen bonds between water and $\mathrm{COOH}$ groups, which increase 


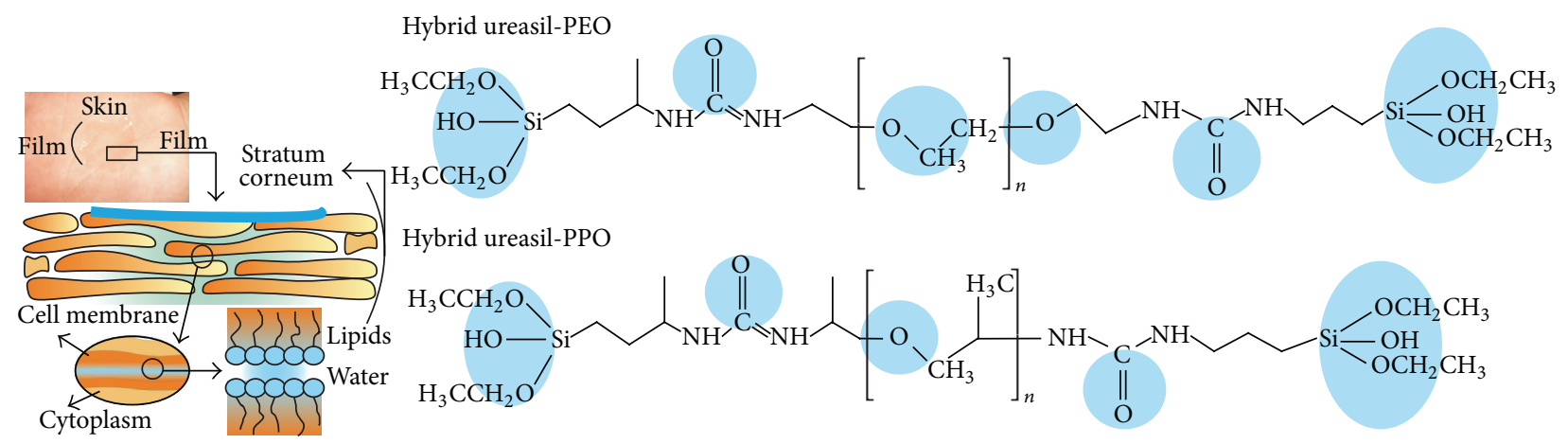

FIGURE 1: The structural formulas of the molecules of ureasil-PEO and ureasil-PPO hybrid materials and the possible sites of bonding with the biological substrate, highlighted in the blue circles.

bioadhesion. However, the oral mucosa is very different from the skin [8]. The stratum corneum has a natural moisture factor (NMF) caused by water-soluble compounds that have the property of absorbing water from the atmosphere and holding it in the deeper layers of stratum corneum, to keep it hydrated [9]. This water in the stratum corneum could also make hydrogen bonds with the $\mathrm{COOH}$ groups, promoting bioadhesion.

The ureasil-polyether hybrid materials are polymers that are constituted by poly(ethylene oxide) (PEO) and poly(propylene oxide) (PPO) chains and by siloxane moieties. The structural formulas of the molecules of ureasil-PEO and ureasil-PPO hybrid materials are shown in Figure 1, revealing the presence of sufficient chemical groups able to form hydrogen bonds $(-\mathrm{OH},-\mathrm{COOH})$ with the biological substrate. The possibility of modifying the molecular weight to control the size and flexibility of the polymer chain makes the ureasil-polyether hybrids a good candidate to form bioadhesive films.

Previous studies [10-12] showed that these ureasilpolyether hybrid materials are usually obtained by hydrolysis and condensation reactions of a functionalized polyether based on PEO or PPO, catalyzed by hydrochloric acid ( $\mathrm{HCl})$. However, reports in the literature also show the possibility of using basic catalysis to produce these materials. The type of catalysis used can alter the structural organization of the film, leading to changes in the bioadhesive forces and in the aesthetic characteristics of the film [13].

The objective of this work was to control the hydrolysis and condensation reactions during the formation of biocompatible films composed of ureasil-PPO and ureasilPEO hybrid materials, with the aim of producing strongly bioadhesive systems to act as skin and wound protectors and potential drug delivery systems for dermal application. For this purpose four different polymers $(2$ hydrophilic and 2 hydrophobic) with differing molecular weights were used to assess the influence of hydrophilic/hydrophobic balance on the characteristics of the bioadhesive materials. The influence of the type of catalysis on the visual characteristics and bioadhesive properties of the films was assessed by using hydrochloric acid $(\mathrm{HCl} 2 \mathrm{M})$ and ammonium fluoride $\left(\mathrm{NH}_{4} \mathrm{~F}\right.$ $0.1 \mathrm{M})$ as catalytic agents.

\section{Materials and Method}

2.1. Preparation of Ureasil Hybrid Materials. The ureasilpolyether hybrid materials were synthesized by the wellknown sol-gel process $[15,16]$. A precursor was prepared from a functionalized polyether, based on poly(ethylene oxide) $\left(\mathrm{NH}_{2}-\mathrm{PEO}-\mathrm{NH}_{2}\right)$ (Mw 500-1900 gmol/L) and poly(propylene oxide) $\left(\mathrm{NH}_{2}-\mathrm{PPO}-\mathrm{NH}_{2}\right)$ (Mw 400-2000 gmol/L), adding a modified alkoxide, 3-(isocyanatopropyl)-triethoxysilane (IsoTrEOS) (molar ratio of the polymer: alkoxide $=1: 2$ ). The sources of these materials were obtained from SigmaAldrich. This solution is normally made up in tetrahydrofuran (THF) [10, 11], but in this study ethanol was used as solvent, to minimize toxic effects, and the solution remained under reflux for $24 \mathrm{~h}$ at a temperature of $60^{\circ} \mathrm{C}$ [17], to promote the formation of the hybrid precursor $(\mathrm{EtO})_{3} \mathrm{Si}-\left(\mathrm{CH}_{2}\right)_{3} \mathrm{NHC}(=\mathrm{O}) \mathrm{NHCHCH}_{3} \mathrm{CH}_{2}$ - (polyether)$\mathrm{CH}_{2} \mathrm{CH}_{3} \mathrm{CHNH}(\mathrm{O}=)-\mathrm{NHC}\left(\mathrm{CH}_{2}\right)_{3} \mathrm{Si}(\mathrm{OEt})_{3}$ [10]. Subsequently the solvent was removed by heating under reduced pressure to form the hybrid precursor. This hybrid precursor was subjected to hydrolysis and condensation reactions [18], promoted by adding ethanol and water and catalyst. Two catalysts were tested, $\mathrm{HCl}$ at a concentration of $2 \mathrm{M}$ and $\mathrm{NH}_{4} \mathrm{~F}$ at a concentration of $0,1 \mathrm{M}$. During these reactions the $\mathrm{OH}$ groups were progressively eliminated, leading to the formation of the films (ureasil-PPO and ureasil-PEO), in which the inorganic-organic networks were joined by covalent bonds [19]. These reactions are shown in Scheme 1.

2.2. Formation of Bioadhesive Films. To investigate the influence of the nature of the catalytic process on the appearance and formation of the films, the precursor hydrolysis and condensation reactions were catalyzed by using two different agents as described in item preparation of ureasil-polyether hybrid materials. $150 \mu \mathrm{L}$ of the ureasil hybrid solutions was applied to the porcine skin with a micropipette. The ureasilpolyether hybrid solutions were also spread on a Tefloncoated acrylic plate with the assistance of a metal spreading device (slot cavity of $0.254 \mathrm{~mm}$ ).

2.3. Cytotoxicity Assay. A material in contact with human tissues should not liberate any component that may be toxic 

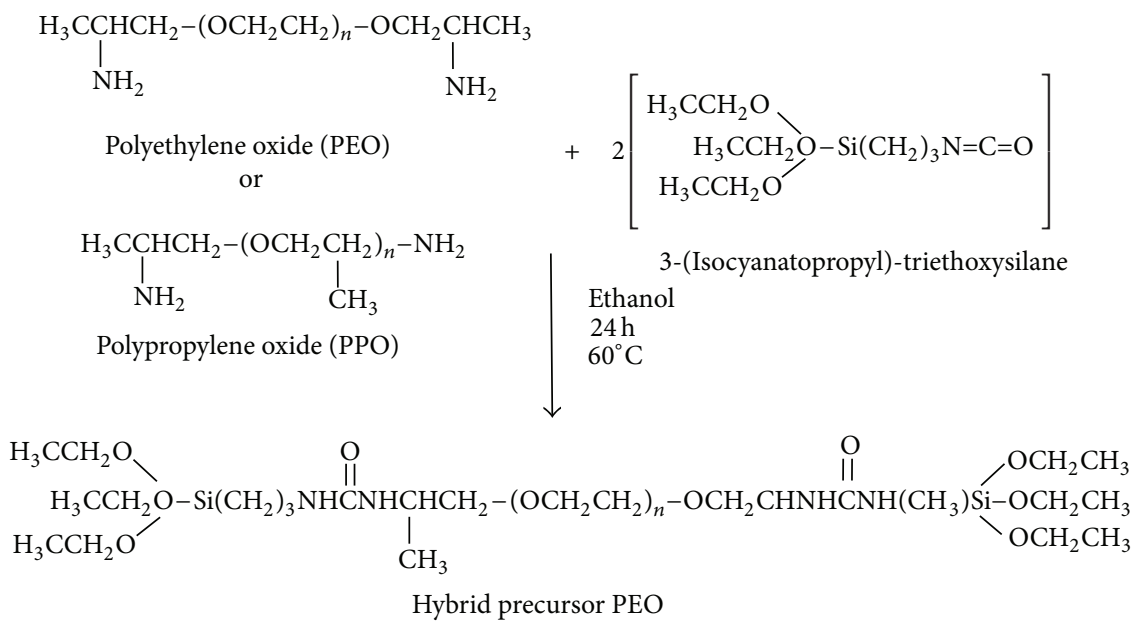

or

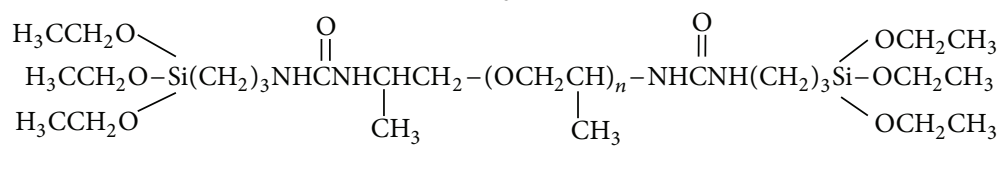

Hybrid precursor PPO
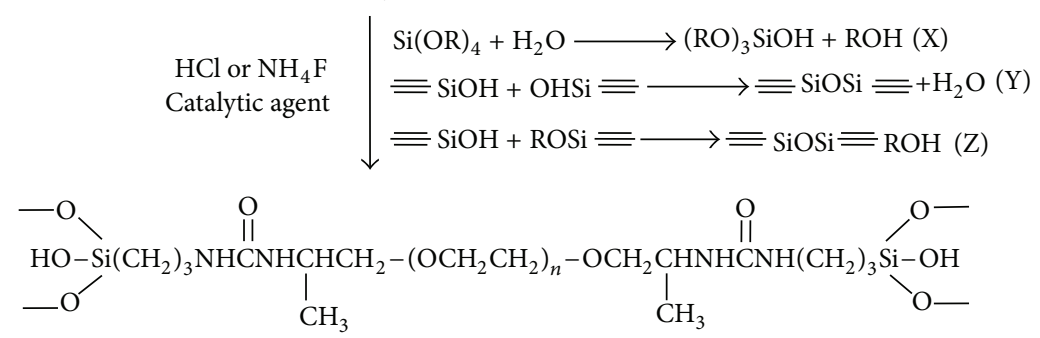

Hybrid PEO

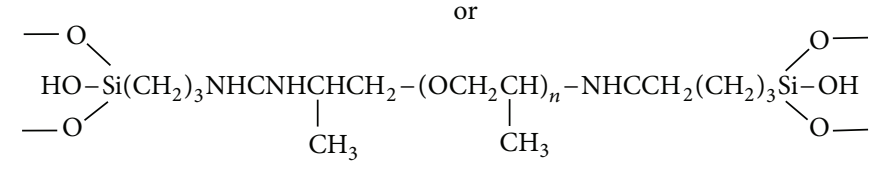

Hybrid PPO

(X): hydrolysis reactions

( $\mathrm{Y}$ and $\mathrm{Z}$ ): condensation reactions

Scheme 1: Scheme for obtaining hybrid materials (adapted from the study by Santilli et al. 2009 [10]).

or have an adverse effect on healing. The cytotoxicity tested described in this work follows the International Standards Organization (ISO/EN 10993) [20] guidelines for testing biomedical materials. The cell viability was assessed by the MTT assay. Human skin keratinocytes $\left(2 \times 10^{5}\right)$ were cultured in DMEM (Dulbecco's Medium Eagle Modified) containing $10 \%$ FBS (fetal bovine serum) in 96-well microplates and exposed to a conditioned medium. The conditioned media were obtained by immersion of the ureasil-polyether hybrid films in DMEM for $24 \mathrm{~h}$. Thereafter, the plates were centrifuged, the supernatants were replaced with MTT dissolved in phosphate buffered saline (PBS), and the cells were incubated in the dark for $4 \mathrm{~h}$. Finally, the medium was aspirated and the MTT reduction product, formazan, was dissolved in isopropyl alcohol and determined spectrophotometrically at $540 \mathrm{~nm}$. The cell concentration was measured against a calibration curve made for the cell line tested with the MTT staining method and the results were expressed as a percentage of the control (untreated cells). All data were expressed as the mean \pm SD of three independent experiments.

2.4. Adhesion Strength Analysis. The tensile strength test was used to assess the bioadhesion of the ureasil-polyether films. The measured resistance to the removal of samples from biological tissue was taken as the bioadhesive strength [21]. In this test a TA.XT Plus Texture Analyser equipped with a Mucoadhesive Test Ring and a $10 \mathrm{~mm}$ diameter cylindrical probe was employed. The biological substrate was porcine ear 
skin, dissected from pigs at a slaughterhouse. To maintain a uniform thickness of substrate a dermatome (Nouvag TCM300, Goldach, EUA) was used, set at $500 \mu \mathrm{m}$ thickness. The skin was then wrapped in a packaging film coated on aluminum foil and frozen at $-2^{\circ} \mathrm{C}$ for a maximum of 30 days. Before the test, the hair was removed with scissors.

The test was performed placing the biological substrate stretched over the top of an acrylic holder and fixed with an acrylic ring, which was fastened with 4 screws. Thereafter, $150 \mu \mathrm{L}$ of the ureasil hybrid solutions was applied to the porcine skin with a micropipette. As soon as the solutions were applied, the cylindrical probe was then lowered at a speed of $1 \mathrm{~mm} / \mathrm{sec}$ until reaching the skin, where it remained in contact with the solution under a downward force of $0.5 \mathrm{~N}$ for 300 seconds. Then, the probe was removed at a speed of $1 \mathrm{~mm} / \mathrm{sec}$ and the tensile force negative to remove it from the polymeric film formed on the pig skin was measured. According to previous studies [22], 300 seconds were enough for the films to become dried, so when the probe was withdrawn on the skin surface, the film was already formed, and so the force of detachment measured was between the skin and the film on dry state. The values of bioadhesion obtained were compared to commercial polymers tested by Souza et al. [14].

2.5. Rheological Measurements. Rheological measurements were made in the oscillatory shear mode with the Carri Med AR 2000 EX Rheometer, employing cone-plate geometry ( $40 \mathrm{~mm}$ diameter). The tension was $40 \mathrm{~Pa}$, the frequency was fixed at $0,5 \mathrm{~Hz}$, and the test continued for $5 \mathrm{~min}$.

2.6. Statistical Analyses. All results obtained in this study are presented as means and standard deviations (SD). The results were compared by ANOVA and post hoc Tukey test. The significance level $(P)$ adopted was 0.05 . Statistical analyses were performed with the program Instat for Windows (Graph Pads software, San Diego, USA).

\section{Results and Discussions}

3.1. Cytotoxicity Assay. A bioadhesive film-forming system for cutaneous application has to adhere to the skin and not to show cytotoxicity. Cytotoxicity is important since the precursor is used directly on the skin and must not harm it, so the catalyst used to promote film formation cannot increase its toxicity.

Therefore the first step in this study was to assess the cytotoxicity employing the MTT reduction test, which is widely used to test the cytotoxicity of biomaterials. Figures 2 and 3 show the cell viability, calculated as described in Section 3.2. The data in Figures 2 and 3 confirm that all ureasil-polyether hybrid materials showed a cell viability greater than $75 \%$ over a period of 24 hours. There was no statistical difference between the values of cell viability of ureasil-PPO and ureasil-PEO hybrid materials catalyzed with $\mathrm{NH}_{4} \mathrm{~F}$ and $\mathrm{HCl}$. Therefore these materials can be considered safe to use, and ureasil-PPO hybrid materials proved to be the less cytotoxic. These results suggest that, although the $\mathrm{HCl}$

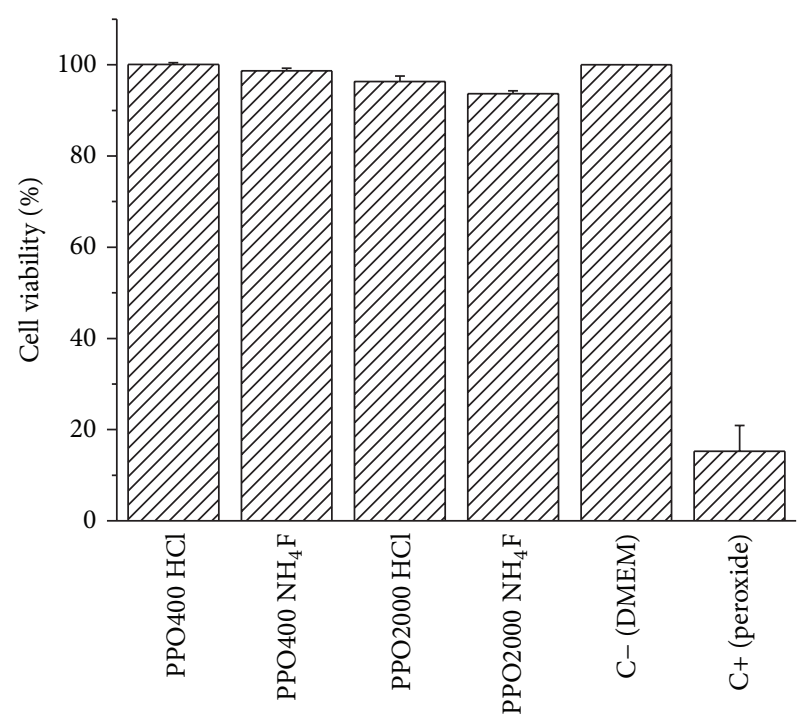

FIGURE 2: Cytotoxicity assay with human skin keratinocytes cells for ureasil-PPO. Results are expressed as the mean \pm SD of triplicates $(n=3)$.

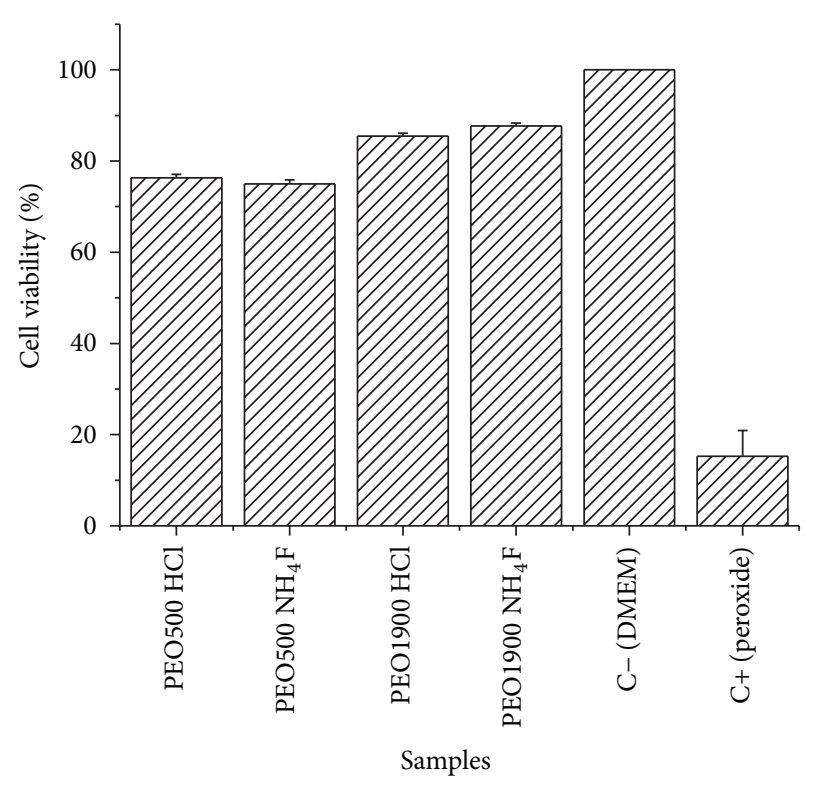

FIgURE 3: Cytotoxicity assay with human skin keratinocytes cells for ureasil-PEO. Results are expressed as the mean \pm SD of triplicates $(n=3)$.

catalyst leads to a $\mathrm{pH}$ more acidic than $\mathrm{NH}_{4} \mathrm{~F}$, both can be used for the formation of films on skin because they caused no cytotoxicity to human skin keratinocytes.

3.2. Formation of Bioadhesive Films. The catalysts influence both, the speed and the mechanism of film formation. Different mechanisms can change the speed of drying process involved in the film formation resulting in structural modifications that can be responsible to irregular film resulting formations [13]. The appearance of the films produced when $\mathrm{HCl}$ and $\mathrm{NH}_{4} \mathrm{~F}$ are used as catalysts is shown in Figures 4 and 5, 


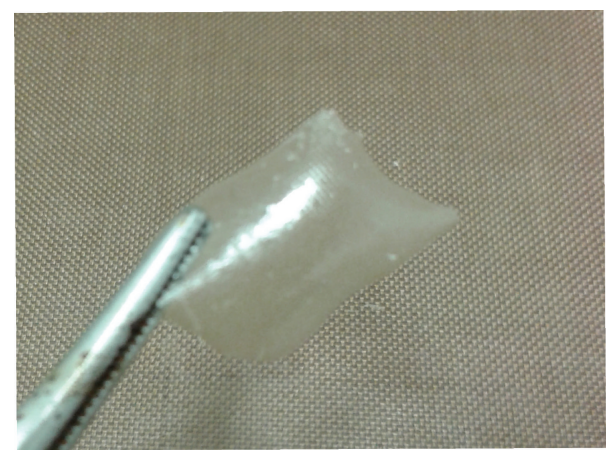

Figure 4: The visual appearance of films produced with $\mathrm{HCl}$ as catalyst agent.

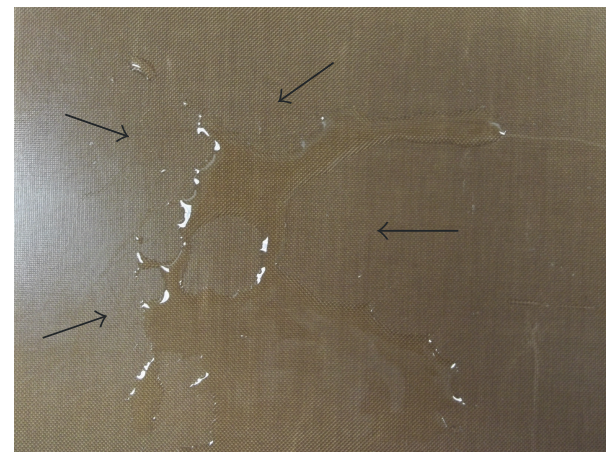

FIgure 5: The visual appearance of films produced with $\mathrm{NH}_{4} \mathrm{~F}$ as catalyst agent.

respectively. It can be seen in the photos that the catalyst influences homogeneity of the films.

The catalyst $\mathrm{NH}_{4} \mathrm{~F}$ led to the formation of an irregular film, whereas $\mathrm{HCl}$ favored the formation of homogeneous and transparent films.

This can be explained by the kinetics of the reactions promoted by the catalyst. When the hydrolytic and condensation step is promoted by basic catalysis, it leads to nucleophilic substitution, where $\mathrm{Si}-\mathrm{OH}$ is the nucleophilic moiety and the $\mathrm{H}_{2} \mathrm{O}$ is removed. Thus, the $\mathrm{Si}-\mathrm{OH}$ group determines the reaction kinetics and results in the formation of more branched chains at the beginning of the process $[23,24]$. The presence of more branched chains leads to a decrease in the rate of hydrolysis and condensation, causing slow and irregular formation films, whereas in hydrolysis and condensation promoted by acid catalysis, the initial reaction of the process leads to the formation of longer and less branched chains $[23,24]$. The acid catalysis reaction is preceded by rapid protonation of the substituents $\mathrm{OR}$ or $\mathrm{OH}$ attached to the $\mathrm{Si}$, increasing the speed of reaction and resulting in a tendency to produce a more linear network, which results in more homogeneous films ( $15 \mathrm{~mm}$ wide and $0.5 \mathrm{~mm}$ thick) $[23,24]$. Thus the catalyst $\mathrm{NH}_{4} \mathrm{~F}$ did not form the film with the expected homogeneity within an acceptable time.

The THF solvent was replaced by ethanol in the hybrid precursor synthesis step (see Section 2.1) because ethanol is biologically and environmentally more appropriate, besides being more cost effective. However, a protic solvent such as ethanol, different from THF, can undergo hydrogen bonding with the catalysts, thus changing the catalytic activity. In this case, with $\mathrm{NH}_{4} \mathrm{~F}$, the presence of ethanol decreases the speed of reaction while it increases the speed of reactions catalyzed by $\mathrm{HCl}$. These factors also influence the visual aspect of the films, as seen in Figures 4 and 5.

\subsection{Adhesion Strength Analysis and Rheological Measure-} ments. Thus modifying the reactions of hydrolysis and condensation by changing the type of the catalyst used can lead to a change in the structure of the hybrid polymeric chains, which can affect the bioadhesion of the films on the skin. Table 1 shows the values of work of bioadhesion force (Wad) for hybrid materials ureasil-PPO and ureasil-PEO with various molecular weights produced with the catalysts $\mathrm{HCl}$ and $\mathrm{NH}_{4} \mathrm{~F}$. It was observed that the molecular weight of the polymer chain is not a factor that determines the adhesive strength of polymers of the same chemical type. The measured adhesion force did not differ statistically between the ureasil-PPO hybrid materials (400 and $2000 \mathrm{gmol}^{-1}$ ), or between the ureasil-PEO hybrid materials of 500 and $1900 \mathrm{gmol}^{-1}$. However, when the strength of bioadhesion was compared between ureasil-PEO and ureasil-PPO hybrid materials with similar molecular weight, it was observed that the value of Wad was significantly greater for ureasil-PEO, irrespective of the catalyst used. This result can be explained by the fact that ureasil-PEO hybrids are more hydrophilic than ureasil-PPO hybrids, since they can interact more efficiently with the water present in the stratum corneum increasing the bioadhesion [9]. Evidently, the bioadhesion force is higher for materials with a more hydrophilic behavior [25].

It can also be observed in Table 1 that replacement of the $\mathrm{HCl}$ catalyst by the $\mathrm{NH}_{4} \mathrm{~F}$ catalyst decreased considerably the adhesion strength.

This may be due to the fact that bioadhesion also depends on the viscosity of the material. To investigate the influence of the catalyst on the viscosity of the films, rheological tests were performed. Figure 6 shows that the viscous modulus $\left(G^{\prime \prime}\right)$ was greater than the elastic modulus $\left(G^{\prime}\right)$ throughout the interval time that is considered ideal for film formation (between 120 and $300 \mathrm{~s}$ ), proving that there was no gel or film formation in samples in which the catalyst $\mathrm{NH}_{4} \mathrm{~F}$ was used. In Figure 7 up to $192 \mathrm{~s}$ it can be observed that the elastic modulus $G^{\prime}$ is similar to the viscous modulus $G^{\prime \prime}$; this time is referred to as gel time or time of film formation. These results confirm the influence of the catalyst on the time profile of the viscosity of materials.

The mechanism involved in the hydrolysis and condensation reactions in the presence of $\mathrm{NH}_{4} \mathrm{~F}$ led to the formation of more branched chains, which resulted in changes in the viscosity of the polymer, resulting in lower bioadhesion [26]. However, comparing these materials with the results obtained by Souza et al. [14] (Table 2), it can be concluded that all materials based on ureasil-PEO used in this study showed significantly greater or similar values of adhesive strength than commercial polymers. 


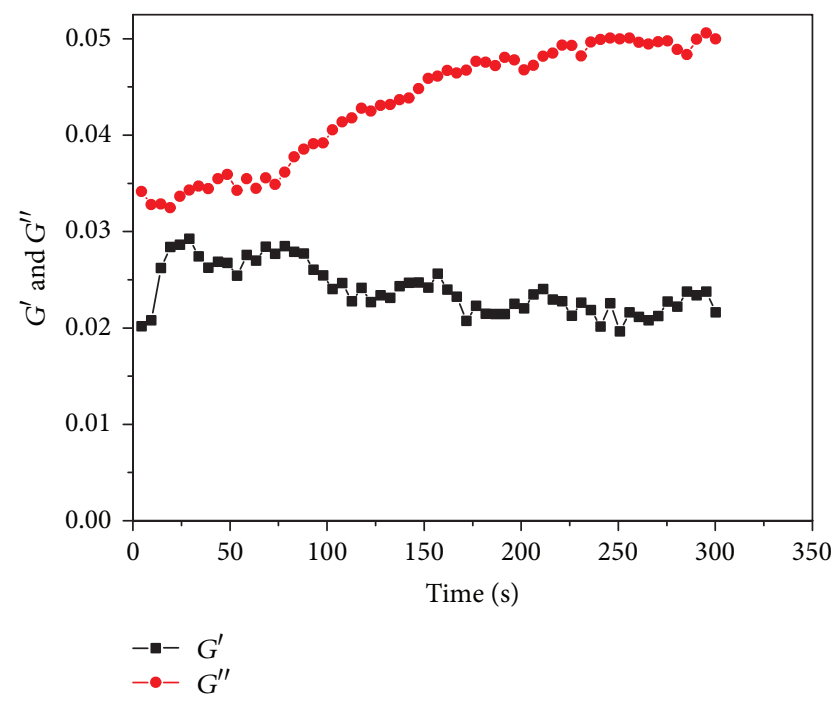

FIGURE 6: Variation in time of $G^{\prime}$ and $G^{\prime \prime}$ for a representative sample of ureasil-PPO or ureasil-PEO, produced with $\mathrm{NH}_{4} \mathrm{~F}$ as catalyst agent.

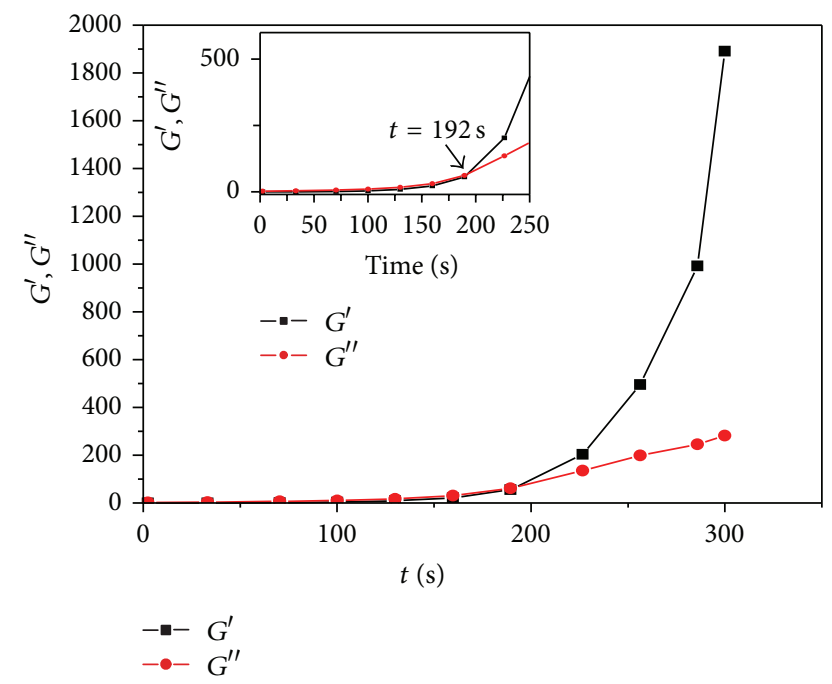

FIGURE 7: Variation in time of $G^{\prime}$ and $G^{\prime \prime}$ for a representative sample of ureasil-PPO or ureasil-PEO, produced with $\mathrm{HCl}$ as catalyst agent.

\section{Conclusions}

The control of the hydrolysis and condensation steps involved in ureasil hybrid film formation is important for the appearance and skin bioadhesivity of the films. The ureasil hybrid films assessed in this study will lead to a potent new technological platform for cutaneous application, since they are able to produce transparent and highly adhesive thin films that are capable of drying quickly and have no cytotoxicity effects. These characteristics meet the requirements for aesthetic attractiveness for this novel approach to drug-delivery systems.
TABLE 1: Values of work of adhesion $\left(W_{\text {ad }}\right)$, for the hybrid ureasilpolyether materials, produced with catalysts $\mathrm{HCl}$ and $\mathrm{NH}_{4} \mathrm{~F}$. Results are expressed as the mean \pm SD for $n=5$ (replicates).

\begin{tabular}{lcc}
\hline $\begin{array}{l}\text { Ureasil-polyether } \\
\text { hybrid material }\end{array}$ & $\begin{array}{c}\left(W_{\text {ad }}\right) \text { Catalyst } \mathrm{HCl}, \\
2 \mathrm{M}\end{array}$ & $\begin{array}{c}\left(W_{\text {ad }}\right) \text { Catalyst } \mathrm{NH}_{4} \mathrm{~F} \\
0,1 \mathrm{M}\end{array}$ \\
\hline PPO 400 & $3.16 \pm 0.28$ & $0.51 \pm 0.06$ \\
PPO 2000 & $2.88 \pm 0.21$ & $0.011 \pm 0.00$ \\
PEO 500 & $5.15 \pm 0.48$ & $1.02 \pm 0.09$ \\
PEO 1900 & $4.96 \pm 0.51$ & $4.85 \pm 0.53$ \\
\hline
\end{tabular}

TABLE 2: Values of work of adhesion $\left(W_{\text {ad }}\right)$ for commercial filmforming materials or adhesive products. Results are expressed as the mean \pm SD for $n=8$ (replicates) [14].

\begin{tabular}{lc}
\hline Polymer & $W_{\text {ad }}(\mathrm{N})$ \\
\hline New-Skin & $0.82 \pm 0.03$ \\
Band-Aid Liquid Bandage & $0.94 \pm 0.02$ \\
Band-Aid Tough-Strips & $2.02 \pm 0.05$ \\
Band-Aid Flexible Fabric & $0.92 \pm 0.03$ \\
\hline
\end{tabular}

\section{Conflict of Interests}

The authors declare that there is no conflict of interests regarding the publication of this paper.

\section{Acknowledgments}

The authors are grateful to FAPESP, CNPq, and PADC/FCFUNESP for the financial support.

\section{References}

[1] B. Aktar, M. Erdal, O. Sagirli, S. Güngör, and Y. Özsoy, "Optimization of biopolymer based transdermal films of metoclopramide as an alternative delivery approach," Polymers, vol. 6, no. 5, pp. 1350-1365, 2014.

[2] G. G. Pereira, S. S. Guterres, A. G. Balducci, P. Colombo, and F. Sonvico, "Polymeric films loaded with vitamin e and aloe vera for topical application in the treatment of burn wounds," BioMed Research International, vol. 2014, Article ID 641590, 9 pages, 2014.

[3] V. Kumar, F. Zakir, G. Agarwal, and A. Choudhary, "Formulation and evaluation of buccal patches of venlafaxine," International Journal of Pharmacy and Biological Sciences, vol. 1, no. 3, pp. 170-182, 2011.

[4] A. Borde, A. Bergstrand, C. Gunnarsson, and A. J. Larsson, "Osmotic-driven mass transport of water: impact on the adhesiveness of hydrophilic polymers," Journal of Colloid and Interface Science, vol. 341, no. 2, pp. 255-260, 2010.

[5] R. F. Donnelly and A. D. Woolfson, "Biodhesive drug delivery systems," in The Polymeric Biomaterials, vol. 2, pp. 311-314, 3rd edition, 2013.

[6] N. A. Peppas and P. A. Buri, "Surface, interfacial and molecular aspects of polymer bioadhesion on soft tissues," Journal of Controlled Release, vol. 2, pp. 257-275, 1985.

[7] D. Duchêne and G. Ponchel, "Bioadhesion of solid oral dosage forms, why and how?" European Journal of Pharmaceutics and Biopharmaceutics, vol. 44, no. 1, pp. 15-23, 1997. 
[8] P. Suresh, K. Manasa, S. S. Babu, B. Brahmaiah, S. Khalillullah, and S. Nama, "Biodhesive drug delivery system-a review," Asian Journal of Pharmaceutical Research, vol. 3, no. 1, pp. 30-37, 2013.

[9] R. Darlenski, S. Sassning, N. Tsankov, and J. W. Fluhr, "Noninvasive in vivo methods for investigation of the skin barrier physical properties," European Journal of Pharmaceutics and Biopharmaceutics, vol. 72, no. 2, pp. 295-303, 2009.

[10] C. V. Santilli, L. A. Chiavacci, L. Lopes, S. H. Pulcinelli, and A. G. Oliveira, "Controlled drug release from ureasil-polyether hybrid materials," Chemistry of Materials, vol. 21, no. 3, pp. 463467, 2009.

[11] E. F. Molina, S. H. Pulcinelli, C. V. Santilli, S. Blanchandin, and V. Briois, "Controlled cisplatin delivery from ureasil-PEO1900 hybrid matrix," Journal of Physical Chemistry B, vol. 114, no. 10, pp. 3461-3466, 2010.

[12] P. C. Barbosa, M. M. Silva, M. J. Smith et al., "Di-ureasil xerogels containing lithium bis(trifluoromethanesulfonyl)imide for application in solid-state electrochromic devices," Electrochimica Acta, vol. 54, no. 3, pp. 1002-1009, 2009.

[13] L. Malfatti and P. Innocenzi, "Sol-gel chemistry: from selfassembly to complex materials," Journal of Sol-Gel Science and Technology, vol. 60, no. 3, pp. 226-235, 2011.

[14] L. K. Souza, C. H. Bruno, L. Lopes, S. H. Pulcinelli, C. V. Santilli, and L. A. Chiavacci, "Ureasil-polyether hybrid film-forming materials," Colloids and Surfaces B: Biointerfaces, vol. 101, pp. 156-161, 2013.

[15] M. C. Gonçalves, V. De Zea Bermudez, R. A. Sá Ferreira, L. D. Carlos, D. Ostrovskii, and J. Rocha, "Optically functional di-urethanesil nanohybrids containing Eu $^{3+}$ ions," Chemistry of Materials, vol. 16, no. 13, pp. 2530-2543, 2004.

[16] L. Lopes, E. F. Molina, L. A. Chiavacci, C. V. Santilli, V. Briois, and S. H. Pulcinelli, "Drug-matrix interaction of sodium diclofenac incorporated into ureasil-poly(ethylene oxide) hybrid materials," RSC Advances, vol. 2, no. 13, pp. 56295636, 2012.

[17] Ro. D. Herculano, C. A. Brunello, J. P. Melo et al., "Novel solid state nitric oxide sensor using siloxano-poly(Oxypropylene) (PPO)," Materials Sciences and Applications, vol. 4, pp. 683-688, 2013.

[18] E. F. Molina, C. R. N. Jesus, L. A. Chiavacci, S. H. Pulcinelli, V. Briois, and C. V. Santilli, "Ureasil-polyether hybrid blend with tuneable hydrophilic/hydrophobic features based on UPEO1900 and U-PPO400 mixtures," Journal of Sol-Gel Science and Technology, vol. 70, no. 2, pp. 317-328, 2014.

[19] E. F. Molina, L. Marçal, H. W. Pereira De Carvalho, E. J. Nassar, and K. J. Ciuffi, "Tri-ureasil gel as a multifunctional organicinorganic hybrid matrix," Polymer Chemistry, vol. 4, no. 5, pp. 1575-1582, 2013.

[20] ISO, "Biological evaluation of medical devices-part 5: test for in vitro cytotoxicity," International Standard (ISO10993-5), 1999.

[21] N. Thirawong, J. Nunthanid, S. Puttipipatkhachorn, and P. Sriamornsak, "Mucoadhesive properties of various pectins on gastrointestinal mucosa: an in vitro evaluation using texture analyzer," European Journal of Pharmaceutics and Biopharmaceutics, vol. 67, no. 1, pp. 132-140, 2007.

[22] I. Zurdo Schroeder, P. Franke, U. F. Schaefer, and C.-M. Lehr, "Development and characterization of film forming polymeric solutions for skin drug delivery," European Journal of Pharmaceutics and Biopharmaceutics, vol. 65, no. 1, pp. 111-121, 2007.
[23] C. J. Brinker, "Hydrolysis and condensation of silicates: effects on structure," Journal of Non-Crystalline Solids, vol. 100, no. 1-3, pp. 31-50, 1988.

[24] C. J. Brinker and G. W. Scherer, Sol-Gel Science: The Physics and Chemistry of Sol-Gel Processing, Academic Press, San Diego, Calif, USA, 1990.

[25] T. M. Kalyankar, N. T. Nalanda, M. Khan, and V. D. Wagh, "Bioadhesive drug delivery systems: a review," Journal of Pharmacy Research, vol. 3, no. 7, pp. 1685-1689, 2010.

[26] R. B. Gandhi and J. R. Robinson, "Oral cavity as a site for bioadhesive drug delivery," Advanced Drug Delivery Reviews, vol. 13, no. 1-2, pp. 43-74, 1994. 

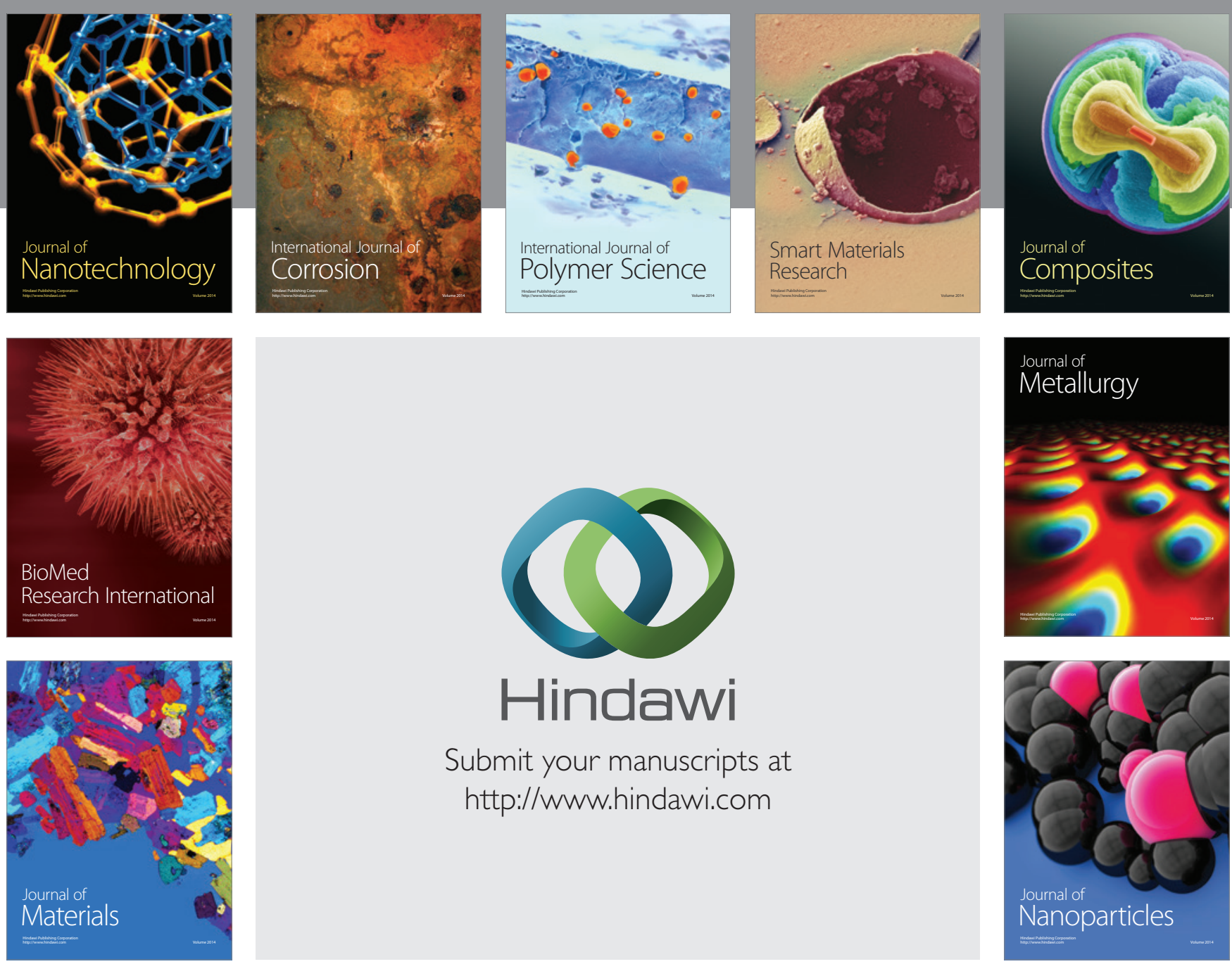

Submit your manuscripts at http://www.hindawi.com
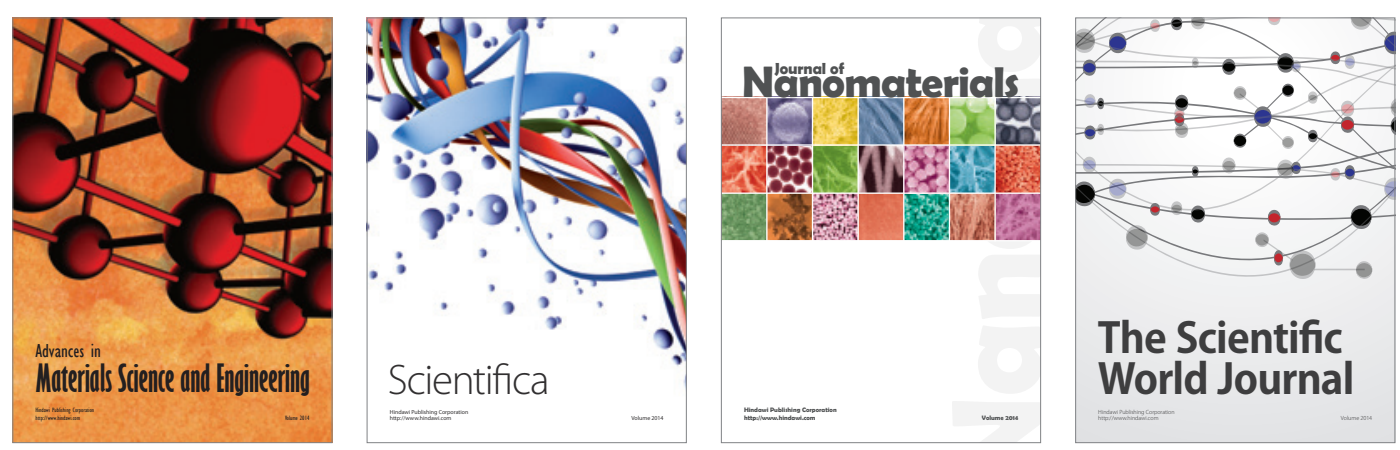

\section{The Scientific World Journal}
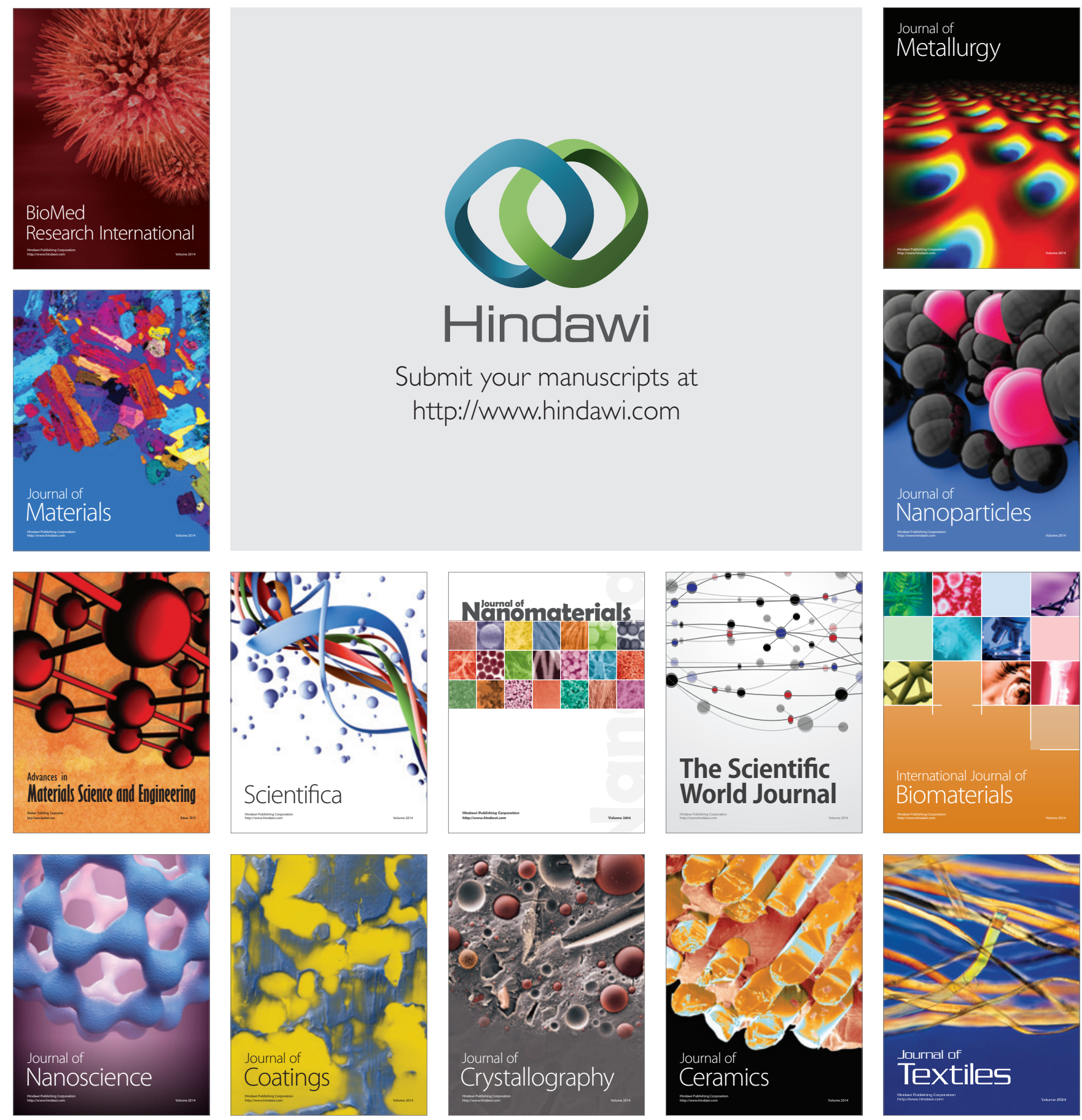